\title{
Population based assessment of uveitis in an urban population in southern India
}

\author{
Lalit Dandona, Rakhi Dandona, Rajesh K John, Catherine A McCarty, Gullapalli N Rao
}

\begin{abstract}
Aim-To assess the prevalence of active and inactive uveitis unrelated to previous surgery or trauma in an urban population in southern India.

Methods-As part of the Andhra Pradesh Eye Disease Study, 2522 subjects $(85.4 \%$ of those eligible), a sample representative of the population of Hyderabad city in southern India, underwent interview and detailed dilated eye examination. Presence of sequelae of uveitis without current active inflammation was defined as inactive uveitis.

Results-Unequivocal evidence of active or inactive uveitis unrelated to previous surgery or trauma was present in 21 subjects, an age-sex adjusted prevalence of $0.73 \%(95 \%$ confidence interval (CI) 0.44-1.14\%). Active uveitis was present in eight subjects, an age-sex adjusted prevalence of $0.37 \%$ (95\% CI $0.19-0.70)$, of which $0.06 \%$ was anterior, $0.25 \%$ intermediate, and $0.06 \%$ posterior. The $0.36 \%(95 \%$ CI $0.17-0.68 \%$ ) prevalence of inactive uveitis included macular chorioretinitis scars $(0.26 \%)$, anterior $(0.07 \%)$ and previous vasculitis involving the whole eye $(0.03 \%)$. The prevalence of visual impairment due to uveitis of less than $6 / 18$ in at least one eye was $0.27 \%$, less than $6 / 60$ in at least one eye was $0.16 \%$, and less than $6 / 60$ in both eyes was $0.03 \%$.
\end{abstract}

Conclusion-These population based cross sectional data give an estimate of the prevalence of various types of uveitis in this urban population in India. Active or past uveitis that might need treatment at some stage was present in one of every 140 people in this population.

(Br f Ophthalmol 2000;84:706-709)

In 1996 we started the population based Andhra Pradesh Eye Disease Study (APEDS) to evaluate the magnitude and causes of visual impairment, prevalence of and risk factors for eye diseases, barriers to eyecare services, and the effect of visual impairment on quality of life, in the state of Andhra Pradesh in southern India. ${ }^{1}$ From the urban segment of APEDS, we have recently reported the prevalence and causes of blindness ${ }^{2}$ and moderate visual impairment, ${ }^{3}$ outcome after cataract surgery, ${ }^{4}$ prevalence of refractive errors ${ }^{5}$ and diabetic retinopathy, ${ }^{6}$ awareness of eye donation, ${ }^{7}$ and utilisation of eyecare services. ${ }^{8}$ In this paper we report the prevalence of active and inactive uveitis unre- lated to previous surgery and trauma from the urban segment of APEDS in a sample representative of the population of Hyderabad city.

\section{Methods}

The sampling and methods of APEDS have been reported in detail elsewhere. ${ }^{1-3}$ The aspects relevant to this paper follow. This study was approved by the ethics committee of the LV Prasad Eye Institute, Hyderabad, India.

The total sample for APEDS was determined as 10 000, 2500 each in one urban and three rural areas. ${ }^{1}$ A multistage sampling procedure was used to obtain the urban sample representative of the 3.5 million population of Hyderabad city in southern India. Twenty four clusters were chosen using stratified random sampling with equal probability of selection. ${ }^{2}$ Oversampling of those above 30 years of age was done by randomly assigning 10 of the selected clusters to have only subjects aged more than 30 years eligible, and the other 14 clusters to have all ages eligible. ${ }^{12}$ Aiming for a recruitment rate of at least $85 \%$, a total of 2954 subjects were sampled to obtain a minimum sample of 2500 subjects.

The sampled subjects were interviewed in detail, ${ }^{1}$ including systemic and ocular history. Systemic history included specific questions on tuberculosis, leprosy, diabetes, hypertension, and severe diarrhoea, followed by a question asking if the subject had any other medical problem which was documented. Subjects were brought to a clinic specially set up for this study. Written informed consent was obtained from them before examination. The examination was performed by two ophthalmologists and two optometrists who had received special training in the procedures of this study. It included presenting and best corrected distance and near $\log M A R$ visual acuity, complete anterior segment examination with slit lamp including applanation tonometry and gonioscopy, and dilatation of pupil unless contraindicated due to risk of angle closure. After dilatation, cataract was graded with standard classification systems, ${ }^{9} 10$ and stereoscopic vitreous and fundus examination was done with the indirect ophthalmoscope using 20 dioptre lens and at the slit lamp using 78 dioptre lens. Particularly for uveitis, documentation was done for the presence and type of keratic precipitates, cells and flare in the anterior chamber, peripheral anterior synechiae, posterior synechiae, cells or exudates in the vitreous, exudates on pars plana or ora serrata, active retinitis or choroiditis or 
Table 1 Age-sex adjusted prevalence of different types of uveitis

\begin{tabular}{|c|c|c|}
\hline \multirow[b]{2}{*}{ Location of uveitis } & \multicolumn{2}{|c|}{$\%$ Prevalence (95\% CI, design effect) } \\
\hline & Active & Inactive \\
\hline Anterior & $0.06(0.01-0.25,1.03)$ & $0.07(0.01-0.26,1.02)$ \\
\hline Intermediate & $0.25(0.09-0.52,1.00)$ & 0 \\
\hline Posterior involving macula & $0.06(0.01-0.25,1.00)$ & $0.26(0.10-0.55,1.00)$ \\
\hline Posterior involving peripheral retina only & 0 & $0^{\star}$ \\
\hline Vasculitis involving whole eye & 0 & $0.03(0-0.22,1.03)$ \\
\hline Total & $0.37(0.19-0.70,1.00)$ & $0.36(0.17-0.68,1.00)$ \\
\hline
\end{tabular}

*The peripheral retinal scars seen could not be unequivocally attributed to past chorioretinitis.

chorioretinitis including vasculitis, and chorioretinitis scars.

Subjects who were physically debilitated and unable to come to the APEDS clinic were examined at home with portable equipment. Gonioscopy and examination with a 78 dioptre lens were not done at home.

Uveitis was considered as anterior if keratic precipitates, cells in anterior chamber, or posterior synechiae were present without signs of inflammation in the vitreous and fundus. Intermediate uveitis was defined as inflammation primarily in the anterior vitreous, ora serrata, or pars plana, ${ }^{11}$ in the form of cells in anterior vitreous or exudates in vitreous or on pars plana or ora serrata. If exudates were present on pars plana or ora serrata, the intermediate uveitis was termed pars planitis. Uveitis in the form of retinitis and/or choroiditis was considered as posterior uveitis. Uveitis was considered as active if cells were present in the anterior chamber or vitreous, or if exudates were present in the vitreous or pars plana or ora serrata, or if ongoing retinitis, choroiditis, or vasculitis were present. In the absence of these features, inactive uveitis was diagnosed in the presence of sequelae of previous uveitis which included keratic precipitates, posterior synechiae, and chorioretinal scars distinctly suggestive of previous chorioretinitis. The subjects diagnosed to have uveitis were referred to the LV Prasad Eye Institute for evaluation. However, since a large majority of them did not come for this evaluation, only anatomical classification of uveitis was possible. The one exception to this was that toxoplasma chorioretinitis was diagnosed if the typical excavated chorioretinal scar with hyperpigmentation was present. $^{12}$

Anterior segment pathology was documented with a Nikon slit lamp camera, and posterior segment pathology with a Zeiss fundus camera.

Age-sex adjustment for the prevalence estimates was done using the demographic structure of Hyderabad. ${ }^{13}$ Design effect of the sampling strategy was calculated from the prevalence in each cluster, ${ }^{14}$ and $95 \%$ confidence intervals (CI) of the estimates adjusted accordingly. Poisson distribution ${ }^{15}$ was assumed for prevalence less than $1 \%$, and normal approximation of binomial distribution for prevalence $1 \%$ or more. The association of uveitis with age, sex, socioeconomic status, and religion was assessed with univariate $\chi^{2}$ analysis and multiple logistic regression. ${ }^{15}$

\section{Results}

Of the sampled 2954 subjects, $2522(85.4 \%)$ were interviewed and examined between October 1996 and June 1997. The age range of these subjects was 1 month to 102 years: 1399 $(55.5 \%)$ were $\geqslant 30$ years old, and 1347 $(53.4 \%)$ female; $23(0.9 \%)$ subjects were examined at home.

In this sample, 21 subjects were found to have unequivocal evidence of uveitis unrelated to previous surgery or trauma, which included one active anterior, six active intermediate, one active posterior, three inactive anterior, nine inactive posterior involving macula, and one old vasculitis involving the whole eye. The age range of these 21 subjects was $12-75$ years, and $11(52.4 \%)$ were female. The age-sex adjusted prevalence of this uveitis was $0.73 \%$ (95\% CI $0.44-1.14 \%)$. There were an additional 33 subjects with small peripheral retinal scars; age-sex adjusted prevalence $1.22 \%$ (95\% CI $0.79-1.65 \%)$. These peripheral scars could not be unequivocally attributed to previous chorioretinitis.

The age-sex adjusted prevalences of the different types of uveitis are shown in Table 1. The distribution of uveitis in the various demographic categories is shown in Table 2. Multiple logistic regression revealed that the odds of having evidence of current or past uveitis were significantly higher in the 40-49 years age group (Table 2).

The age of those with active uveitis (mean 26 years, 95\% CI 15.4-36.6 years) was lower than that of those with inactive uveitis (mean 44.4 years, 95\% CI 33.6-55.1 years). Of the eight cases of active uveitis, one was anterior with cells and flare in the anterior chamber and old granulomatous keratic precipitates in one eye of a 12 year old female, six were intermediate of which two were pars planitis, and one was posterior with chorioretinitis in the macula of one eye of a 15 year old male.

Eight subjects had best corrected distance visual acuity less than $6 / 18$ in at least one eye due to uveitis, an age-sex adjusted prevalence of $0.27 \%(95 \%$ CI $0.10-0.55 \%)$. Of these, uveitis was responsible for best corrected distance visual acuity less than $6 / 60$ in at least one eye in four subjects (prevalence $0.16 \%$ ), and less than $6 / 60$ in both eyes in one subject (prevalence $0.03 \%$ ). These eight subjects with visual impairment due to uveitis included one with active chorioretinitis in the macula, six with chorioretinitis scars in the macula (four compatible with toxoplasma), and one with history of retinal vasculitis leading to neovascular glaucoma which was treated with cyclocryotherapy. Seven of the nine chorioretinitis scars in the macula were compatible with the clinical diagnosis of previous toxoplasma chorioretinitis.

Of the 10 subjects with active or inactive anterior or intermediate uveitis, four $(40 \%)$ gave a history of ocular symptoms-that is, redness, pain, or visual disturbance. Of these four subjects with symptoms, only two had sought treatment. Of the seven subjects with vision loss due to macular chorioretinitis or chorioretinitis scar, only three had sought 
Table 2 Distribution of uveitis with univariate analysis and multiple logistic regression

\begin{tabular}{|c|c|c|c|}
\hline & $\begin{array}{l}\text { Total in } \\
\text { group }\end{array}$ & $\begin{array}{l}\text { No with } \\
\text { uveitis }\end{array}$ & $\begin{array}{l}\text { Prevalence } \\
(\%)\end{array}$ \\
\hline \multicolumn{4}{|l|}{$\mathrm{Age}^{\star}$ (years) } \\
\hline$\leqslant 15$ & 663 & 3 & 0.45 \\
\hline $16-29$ & 460 & 3 & 0.65 \\
\hline $30-39$ & 465 & 5 & 1.08 \\
\hline $40-49$ & 395 & 7 & 1.77 \\
\hline $50-59$ & 260 & 0 & 0 \\
\hline $60-69$ & 184 & 1 & 0.54 \\
\hline$\geqslant 70$ & 95 & 2 & 2.11 \\
\hline \multicolumn{4}{|l|}{ Sext } \\
\hline Male & 1175 & 10 & 0.85 \\
\hline Female & 1347 & 11 & 0.82 \\
\hline \multicolumn{4}{|c|}{ Socioeconomic status $\ddagger \$} \\
\hline Upper & 267 & 2 & 0.75 \\
\hline Middle & 1033 & 6 & 0.58 \\
\hline Lower & 920 & 9 & 0.98 \\
\hline Extreme lower & 232 & 4 & 1.72 \\
\hline \multicolumn{4}{|l|}{ Religion } \\
\hline Hindu & 1556 & 15 & 0.96 \\
\hline Muslim & 908 & 6 & 0.66 \\
\hline \multirow[t]{2}{*}{ Other } & 58 & 0 & 0 \\
\hline & \multicolumn{2}{|c|}{$\begin{array}{l}\text { Odds ratio for having } \\
\text { uveitis with multiple } \\
\text { logistic regression }\end{array}$} & $\begin{array}{l}95 \% \\
\text { confidence } \\
\text { interval }\end{array}$ \\
\hline \multicolumn{4}{|l|}{ Age (years) } \\
\hline$\leqslant 15$ & 1.00 & & \\
\hline $16-29$ & 1.48 & & $0.30-7.43$ \\
\hline $30-39$ & 2.29 & & $0.54-9.67$ \\
\hline $40-49$ & 3.91 & & $1.01-15.30$ \\
\hline $50-59$ & 0.01 & & 0 to $>10^{11}$ \\
\hline $60-69$ & 1.24 & & $0.13-12.06$ \\
\hline$\geqslant 70$ & 5.09 & & $0.83-31.08$ \\
\hline \multicolumn{4}{|l|}{ Sex } \\
\hline Male & 1.00 & & \\
\hline Female & 0.93 & & $0.39-2.22$ \\
\hline \multicolumn{4}{|c|}{ Socioeconomic status $\S$} \\
\hline Upper & 1.00 & & \\
\hline Middle & 0.80 & & $0.16-4.04$ \\
\hline Lower & 1.35 & & $0.29-6.35$ \\
\hline Extreme lower & 2.61 & & $0.47-14.60$ \\
\hline \multicolumn{4}{|l|}{ Religion } \\
\hline Hindu & 1.00 & & \\
\hline Muslim & 0.67 & & $0.26-1.74$ \\
\hline Other & 0.01 & & 0 to $>10^{26}$ \\
\hline
\end{tabular}

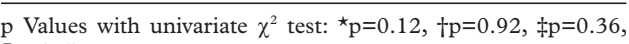
Ip $=0.57$.

Socioeconomic status: extreme lower (monthly per capita income in rupees) $\leqslant 200(£ 3.20)$, lower $(201-500)$, middle (501-2000), and upper $(>2000)$.

treatment. The one subject with vision loss due to vasculitis had sought treatment.

None of the subjects with uveitis in this cross sectional study gave a history of systemic disease that could be associated with uveitis. The majority of these did not report for further systemic evaluation and, therefore, it is not possible reliably to assess the association of uveitis with systemic disease from these data.

\section{Discussion}

Population based assessment of a disease assists in assessing its magnitude in the population and in estimating the need for services for that disease. This paper reports such data for uveitis in an urban population in southern India. Approximately one of every 140 people in this population had evidence of current or past uveitis unrelated to previous surgery or trauma, who might need treatment for uveitis at some stage.

The prevalence of intermediate uveitis and that of active or past posterior uveitis involving the macula was almost the same. Although uveitis limited only to the anterior chamber was somewhat less common than intermediate and posterior macular uveitis, since all cases of intermediate uveitis were associated with some evidence of active or past inflammation in the anterior chamber, the prevalence of active or past anterior chamber inflammation was not less than intermediate or posterior macular uveitis. It is possible that some cases of previous acute anterior uveitis which did not leave sequelae could have been missed in our cross sectional study, thereby leading to its underestimation. In contrast, intermediate and posterior uveitis are more likely to be chronic and, therefore, the chance of their underestimation would be less.

It is a limitation of our study that the majority of the subjects with uveitis referred for systemic examination did not report for this evaluation. Therefore, it is not possible from our data to assess the possible aetiologies of the uveitis seen. The one exception to this was that majority of the chorioretinitis scars in the macula were compatible with toxoplasma. ${ }^{12}$

The data reported in this paper suggest that uveitis causes visual impairment of less than $6 / 18$ in at least one eye in about one in every 370 people in this population, and less than $6 / 60$ in at least one eye in about one of every 625 people. In our sample, the visual impairment due to uveitis was mostly the result of posterior macular uveitis, suggesting that this is the commonest cause of visual impairment due to uveitis in our population.

These population based data from an urban population in southern India give an estimate of the magnitude of uveitis, the anatomical types of uveitis, and the visual impairment caused by uveitis in this population. Recent and reliable population based data on eye diseases and the visual impairment caused by them are necessary for appropriate planning of eyecare services. ${ }^{16}{ }^{17}$

Financial support for this study was provided by the Hyderabad Eye Research Foundation. Rakhi Dandona is supported in part by the RB McComas and Hugh Noel Puckle Scholarship from the University of Melbourne. The authors would like to thank Professor Hugh R Taylor for guidance in the design of the Andhra Pradesh Eye Disease Study; Partha Mandal, and M Srinivas for contributing to the clinical examination; and Pyda Giridhar, V Nagaraja Naidu, Kovai Vilas, and MN Prasad for recruiting and interviewing the study participants.

1 Dandona R, Dandona L, Naduvilath TJ, et al. Design of a population-based study of visual impairment in India: the Andhra Pradesh Eye Disease Study. Indian f Ophthalmol 1997;45:251-7.

2 Dandona L, Dandona R, Naduvilath TJ, et al. Is current eye-care-policy focus almost exclusively on cataract adequate to deal with blindness in India? Lancet 1998;351: 1312-6.

3 Dandona L, Dandona R, Naduvilath TJ, et al. Burden of moderate visual impairment in an urban population in moderate visual impairment in an urban popula

4 Dandona L, Dandona R, Naduvilath TJ, et al. Populationbased assessment of the outcome of cataract surgery in an urban population in southern India. Am $\mathcal{F}$ Ophthalmol 1999;127:650-8.

5 Dandona R, Dandona L, Naduvilath TJ, et al. Refractive errors in an urban population in southern India: the Andhra Pradesh Eye Disease Study. Invest Ophthalmol Vis Sci 1999;40:2810-8.

6 Dandona L, Dandona R, Naduvilath TJ, et al. Population based assessment of diabetic retinopathy in an urban population in southern India. Br F Ophthalmol 1999;83:937-40.

7 Dandona R, Dandona L, Naduvilath TJ, et al. Awareness of eye donation in an urban population in India. Aust NZ $\mathcal{F}$

8 Dandona R, Dandona L, Naduvilath TJ, et al. Utilisation of eyecare services in an urban population in southern India:

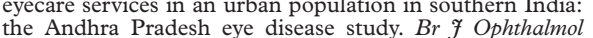
2000;84:22-7.

9 Chylack LT, Wolfe JK, Singer DM, et al. The lens opacity classification system III. Arch Ophthalmol 1993;111:831-6. 
10 Taylor HR, West SK. A simple system for the clinical grading of lens opacities. Lens Res 1988;5:175-81.

11 Zimmerman PL. Pars planitis and other intermediate uveitis. In: Yanoff M, Duker JS, eds. Ophthalmology. London: Mosby, 1999:

12 Khanna A, Goldstein DA, Tessler HH. Protozoal posterior uveitis. In: Yanoff M, Duker JS, eds. Ophthalmology. London: Mosby, 1999: section 10, chapter 14:1-6.

13 Chief Planning Officer. Handbook of statistics Hyderabad district 1993-94. Hyderabad, 1994.
14 Bennet S, Woods T, Liyanage WM, et al. A simplified general method for cluster-sample surveys of health in developing countries. World Health Stat Quart 1991;44:98106.

15 Rosner B. Fundamental of biostatistics. 2nd ed. Boston: PWS Publishers, 1986:84-92,404-8.

6 Dandona L. Improving health in India. Lancet 1998;352:328. 7 Dandona L. Blindness-control policy and population-based surveys in India. [editorial] Indian f Ophthalmol 1999;47: $61-2$. 